\title{
Important Source of Guram Rcheulishvili Biobibliography - His Unknown Archive Material
}

\author{
Dr. Esma Mania \\ Korneli Kekelidze Georgian National Center of Manuscripts, Georgia
}

\begin{abstract}
:
A biographical record of the life and work of a public figure, their biobibliography, is a chronologically organized form of the facts and events of his life. Therefore, the main vector of fundamental research performed for perfection of chronicles is directed to accurate or approximate dating facts and undated works.

Famous Georgian writer Guram Rcheulishvili's fiction and documentary heritage, as well as his personal correspondence are published in 6 volumes, but in his personal archive, there is kept an unknown, unpublished documentary material that is of particular importance to biobibliography. For example, a swimming pool permit, a business card, medical analysis, payment receipts, official orders, praise certificates, greeting cards, invitations, a log book, photos, correspondence with others that mention a research person ... Often these archival units provide invaluable data for fact-finding and dating. They are often an indirect source of related facts, events, or dates. They tell us where the person was, what he was occupatied with, and what were his interests and spiritual aspirations. Also it is important to decrypt textual (writer's notes and graphical reflexes made on official documents as his reaction and resonance ...) and diplomatic (official seals, facsimiles, formal-style formulas of performing the work ...) information written and placed on the above-mentioned artifacts and use them for the needs of research.
\end{abstract}

keywords: artifacts; chronicles; heritage; dating; correspondence 